\title{
Changes in students' mental models from computational modeling of gene regulatory networks
}

\author{
Joseph T. Dauer ${ }^{1 *}$ D, Heather E. Bergan-Roller ${ }^{2}$, Gretchen P. King ${ }^{1}$, McKenzie Kjose ${ }^{1}$, Nicholas J. Galt ${ }^{3}$ and
} Tomáš Helikar ${ }^{4}$

\begin{abstract}
Background: Computational modeling is an increasingly common practice for disciplinary experts and therefore necessitates integration into science curricula. Computational models afford an opportunity for students to investigate the dynamics of biological systems, but there is significant gap in our knowledge of how these activities impact student knowledge of the structures, relationships, and dynamics of the system. We investigated how a computational modeling activity affected introductory biology students' mental models of a prokaryotic gene regulatory system (lac operon) by analyzing conceptual models created before and after the activity.

Results: Students' pre-lesson conceptual models consisted of provided, system-general structures (e.g., activator, repressor) connected with predominantly incorrect relationships, representing an incomplete mental model of gene regulation. Students' post-lesson conceptual models included more context-specific structures (e.g., cAMP, lac repressor) and increased in total number of structures and relationships. Student conceptual models also included higher quality relationships among structures, indicating they learned about these context-specific structures through integration with their expanding mental model rather than in isolation.

Conclusions: Student mental models meshed structures in a manner indicative of knowledge accretion while they were productively re-constructing their understanding of gene regulation. Conceptual models can inform instructors about how students are relating system structures and whether students are developing more sophisticated models of system-general and system-specific dynamics.
\end{abstract}

Keywords: Undergraduate, Modeling instruction, Conceptual model, Computational model, Mental models, Gene regulation

\section{Introduction}

Modeling and model-based reasoning are important scientific processes that encompass the way scientists interact with phenomena (S. W. Gilbert 1991; Jungck 2011). There are different types of modeling practices that fall under the umbrella of model-based reasoning, including visual modeling and thought-experiments (Nersessian 1999; Seel 2017). Modeling (frequently coupled with simulations) is a skill that develops over time and is considered a core competency for postsecondary biology

\footnotetext{
* Correspondence: joseph.dauer@unl.edu

${ }^{1}$ School of Natural Resources, University of Nebraska-Lincoln, 3310 Holdrege

St, 524 Hardin Hall, Lincoln, NE 68583, USA

Full list of author information is available at the end of the article
}

students (AAAS 2011). Modeling can involve a spectrum of skills from passive observation of graphs to creation and interpretation of models ranging from conceptual to computational (Eaton et al. 2019; Garfunkel and Montgomery 2016). Moreover, scientists engage in modeling for many reasons, including exploring dynamics of complex systems, developing conceptual frameworks, making predictions, and generating causal explanations (Nersessian 2009; Odenbaugh 2005; Svoboda and Passmore 2013). Modeling allows scientists to synthesize current knowledge, represent complex systems, interrogate their dynamics, and develop, prioritize, and test hypotheses prior to performing expensive and lengthy laboratory experiments (Hallström and Schönborn 2019; Odenbaugh 2005). At the same time, 
modeling can prompt experiments on mechanisms and tests of predictive outcomes.

Because modeling is so intricately tied to scientists' work, it follows that modeling should be reflected in classroom practices where students can develop skills necessary to reveal the mechanisms of phenomena, like scientists. Creating a model is part of the modeling process that also includes practices like making predictions, evaluating data outcomes, and revising the model (Brewe 2008; Fretz et al. 2002; Sins et al. 2005). Models are an abstraction of real biological phenomena and should vary depending on the modeler's knowledge of the system, purpose (i.e., scope) of the model, and ability to represent their mental model for their intended audience. This paper considers three types of models: mental models, conceptual models, and computational models, and we define their relationships below and in Fig. 1.

Mental models are the knowledge structures residing in our brains for the biological phenomena we observe (Ifenthaler et al. 2011; Seel 2017). An instantiation of a mental model can be externalized (although not required) as a conceptual model created by the modeler and depicts the structures and relationships necessary to represent the phenomena (Shavelson et al. 2005). In this work, the conceptual models of prokaryote gene regulation were created within specific bounds provided by the instructor (details provided in the "Methods" section). Conceptual models allow for thought-experiments whereby students consider the potential biological outcomes from interactions represented in their models and have opportunities to compare their outcomes to observations or consensus, scientific models.
Instructors play a critical role in fostering cognitive development of student modeling ability as they create opportunities to construct, manipulate, and evaluate conceptual models (Bray-Speth et al. 2014; Brewe 2008). Unfortunately, postsecondary students have few and irregular opportunities for modeling in biology despite evidence that modeling has been shown to be an effective way of developing deep disciplinary understanding (Mulder et al. 2016; Seel 2017). Importantly, constructing and interpreting conceptual models focuses student attention on the relationships within the model rather than the structures in isolation (Dauer et al. 2013; Hmelo-Silver et al. 2007; Jordan et al. 2008). With student attention focused on relationships, instructors can challenge students to consider the system dynamics and complexity that emerges from variation in the structures, network-like relationships, and dynamics (Dauer and Dauer 2016; Williams and Clement 2015). When the relationships among structures can be described mathematically or computationally in a model, the dynamics of the system can be revealed through simulation (AbouJaoudé et al. 2016). Computer simulations allow for the exploration of computational and mathematical models and permit students to adjust biological settings to repeatedly manipulate a multitude of variables (de Jong and van Joolingen 1998; Rutten et al. 2012). Simulations afford opportunities to repeat computational experiments, evaluate their results against expected outcomes, and revise one's mental model about relationships (Seel 2017; Soderberg and Price 2003).

Importantly, conceptual and computational models can be assessed and therefore inform the instructor

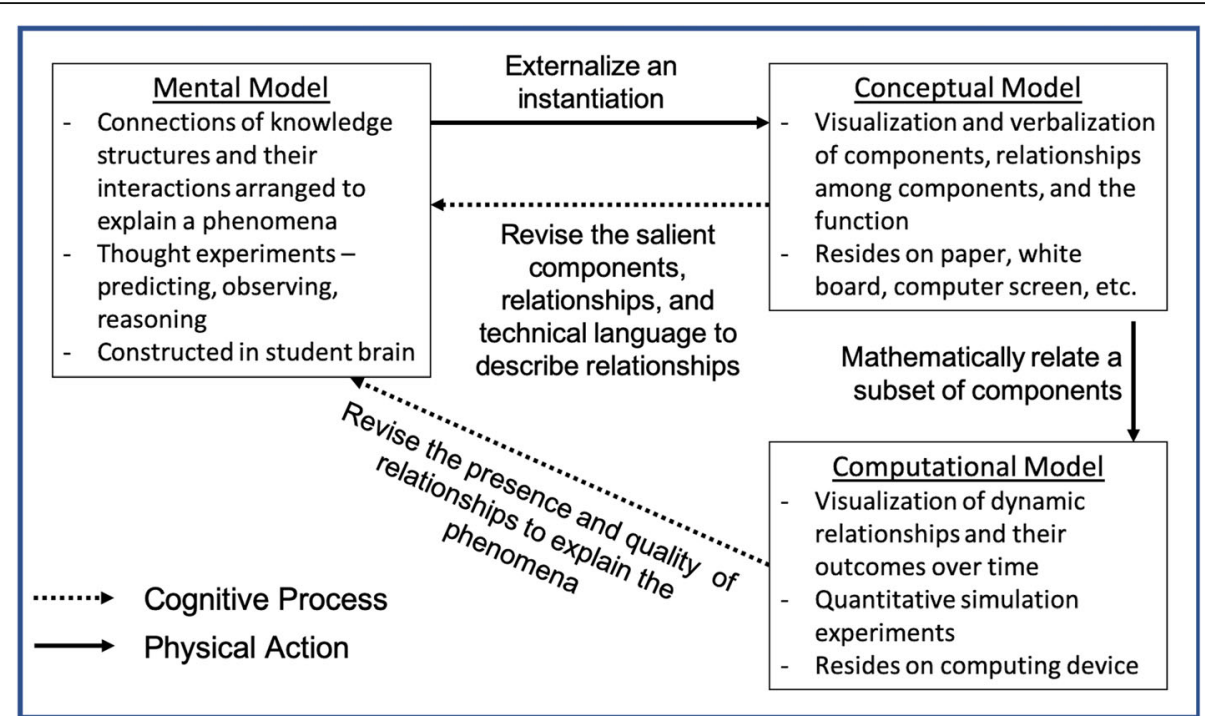

Fig. 1 Biological phenomena are complex interactions of system structures and can be represented by models (boxes) of the structures, relationships, and dynamics that reside in different spaces. There are physical actions (solid arrows) that externalize and mathematize mental and conceptual models and cognitive processes (dotted arrows) that feedback to the student's mental model of the biological system 
about a student's current and changing mental model (and hence understanding) of the phenomena (Fig. 1). Instructors can support the construction of computational models by providing partially worked out models to expand (Mulder et al. 2016), offering opportunities to compare multiple models, and between models and experiments (Fuhrmann et al. 2018; Schwarz et al. 2009). Computational model-based activities have been firmly established as improving learning in science, especially when used as a support rather than replacement of other teaching approaches (Rutten et al. 2012; Smetana and Bell 2012). While these reviews describe research on whether computational models are helpful, what is less clear is how computational models impact students' mental models.

Creating, interpreting, and conducting thought experiments with conceptual models will positively impact students' mental models (Seel 2017). Pairing conceptual models with empirical observations of simulated aquaria had dramatic impacts on student-drawn models of nitrogen cycles (Vattam et al. 2011). Similarly, coupling secondary students' computer modeling with experimentation improved learning of diffusion and osmosis (Fuhrmann et al. 2018). Conceptual models created repeatedly during a course helped students reorganize and expand students' knowledge of the genetic basis of evolution (Dauer et al. 2013) and earth systems (Pearsall et al. 1997). During conceptual model formulation, the iterative process of comparison between the created model and mental model and observations move students towards more sophisticated theories about the phenomena (Louca and Zacharia 2012; Windschitl et al. 2008). Students connect their prior knowledge to new experiences, ideas, and knowledge and can lead to students accreting new knowledge to their mental model, revision of relationships among structures, and pruning of extraneous relationships and structures (Louca and Zacharia 2012; Rumelhart and Norman 1978). This means students are developing more technically (or disciplinary) accurate relationships between system structures as they learn to know the system not only by its structures, but also by how those structures are related to each other. The next step is making the transition from relation-based thinking (i.e., describing relationships) to system-based thinking that links the relationships to the mechanism of the observable phenomena (Louca and Zacharia 2012).

When conceptual models of biological systems are described mathematically and computationally, there can be important benefits for students' mental model about how the system functions, i.e., the system dynamics. While students' conceptual models can show an instructor if students are relating specific structures, there is little information about the strength of those relationships and the relative impact of those relationships on overall model functioning. For example, a relationship may be present in the biological system, but only impact system functioning under very specific environmental conditions or be conditionally dependent on the presence of other structures. Once relationships are described mathematically in a computational model, students' mental models can be compared to model outputs (e.g., data tables, figures) to reinforce or eliminate specific relationships or series of relationships to better explain the mechanism of the phenomena. Bodemer et al. (2005) demonstrated that students who actively interacted with content to insert it into computer representations of figures had significantly greater learning gains and investigated their models more systematically than their peers who used pre-integrated figures or figures separate from content, as might be expected from students reading a textbook. Therefore, students who actively engage the dynamic relationships would be expected to reinforce those connections in their mental models or add new connections to explain the observed outcomes. This process will, inevitably, revise the students' mental model and therefore lead to a new instantiation of that mental model that may be externalized in a conceptual model.

Therefore, conceptual models serve a dual purpose: one for students and one for instructors. It is instructors' goal to facilitate conceptual change that is manifested by development of an increasingly sophisticated mental model that can explain the general phenomena and be applied to specific contexts. Conceptual models prepare students to simulate system dynamics using computational model reasoning and inform instructors of students' current and changing knowledge of the system (i.e., students' mental model of the phenomena). For students, the effort needed to create a conceptual model challenges them to access their prior knowledge about structures in the system (e.g., DNA, mRNA, proteins) and prepares them to consider how these structures interact to regulate gene expression. A student's conceptual model helps the instructor visualize students' knowledge about the relationships, which structures the students deemed were central or peripheral to the system, and their knowledge of the particular context (Ifenthaler et al. 2011). Students' conceptual models will change when their mental models are re-constructed as they add context-specific structures, connect these structures, and utilize a computational model to causally explain the biological outcomes (Bodemer et al. 2005; Smetana and Bell 2012).

For this study, the general phenomenon of interest was gene regulation. How, when, where, and under what environmental conditions genes are transcribed into proteins (i.e., gene regulation) underlies the diversity in organisms' forms and functions (Cooper 2015) and is a core conceptual idea for postsecondary students in the 
USA (Brownell et al. 2014). While eukaryotes have complex regulatory mechanisms, postsecondary biology students frequently begin with the comparatively simple regulatory mechanisms of prokaryotic organisms. In prokaryotes, protein-coding genes that are part of the same pathway are often located together in an operon regulated by a single promoter region and transcribed into a single mRNA. Typically, students learn about the trp and lac operons, which have different regulatory mechanisms: the trp operon is repressible and the lac operon is inducible (Stefanski et al. 2016). The long-term benefit for students is to establish a foundation about how molecular components work together to regulate gene expression and, as students advance in their curricula, allow students to apply this general mental model to other gene regulatory networks (Esmaeili et al. 2015).

We investigated changes in students' conceptual models and asked two research questions: (1) what do conceptual models reveal about changes in students' mental models of gene regulation and (2) how do students apply this mental model during a computational modeling activity? We hypothesized that completing computational modeling activities would improve students' knowledge of the structures and relationships of gene regulation by reinforcing, replacing, removing, and improving quality of the relationships within the system. We analyzed pre-lesson and post-lesson conceptual models to describe changes in students' mental models induced by completing computational modeling activities based on the lac operon system of regulation of gene expression in prokaryotes. Pre-lesson conceptual models determined students' baseline knowledge about relationships that could impact prokaryote gene regulation. Comparison of pre to post conceptual models helped explain how a computational modeling activity impacted students' ability to reconcile a specific context with their mental models of gene regulation.

\section{Methods}

\section{Study context}

The study was conducted over two terms (fall 2015 and spring 2016) in the same academic year with students enrolled in the first of a two-part sequence of introductory biology lecture and laboratory courses for life science majors at the University of Nebraska-Lincoln in the USA. The first course in this sequence focuses on cell biology. Data were collected during one 3-h lab period in week 14 or 15 of the 16-week term. Consenting students in both terms (fall-179 students; spring-159) were demographically similar: percent of students that were female (2015-116, 66\%; 2016-116, 74\%), age (2015-median was 19 years; 2016-19), and percent white/non-Hispanic (2015-88\%; 2016-84\%). Prior to the lac operon modeling activity, students in both terms had completed two computational modeling activities (weeks 4 and 8 ) on cellular respiration and cell cycle.

\section{Computational modeling lesson}

The computational modeling lesson deployed in this study was designed to improve student conceptual understanding of the structures, processes, and molecules of gene regulation in the context the lac operon (Crowther et al. 2019). The modeling lesson leverages a constructivist approach, whereby students can learn about the biological system by building and interrogating the dynamics of the modeled system. The lesson is detailed in Crowther et al. 2019 and freely available in the Cell Collective systems modeling and simulation platform (https://cellcollective. org; Helikar et al. 2012, Helikar et al. 2015). In the lac operon, the genes code for proteins that import and break down lactose into galactose and glucose. In the human gut, prokaryotes such as E. coli may activate the lac operon when lactose is present (and glucose is absent) to produce glucose for cellular respiration.

Students $(n=345$; of which 338 provided research consent) were assigned a concise reading about E. coli and its metabolism prior to attending the laboratory session where the modeling activity took place. During the lesson, students were provided with a pre-constructed computational model and they predicted, tested, recorded, and explained their findings in scenarios related to "perturbing the system" through nutritional or mutational variations in structures of the modeled system. In a series of investigations, students discovered how the presence and absence of glucose and lactose affected the molecular interactions and ultimately resulted (or not) in operon transcription. Students also introduced mutated versions of proteins to determine how inactive molecules impacted transcription.

\section{Pre- and post-lesson conceptual model construction}

Students' mental models were assessed with conceptual models before (pre) and after (post) the computational modeling lesson. Students were asked to show how the given structures interact to affect transcription (Supplemental materials S1). Provided structures were general terms related to mechanisms of gene regulation (e.g., activator, repressor), not names of molecules involved in the regulation of the lac operon (e.g., CAP). Pre and post models were purposefully general because the mental model we hoped to elicit was focused on gene regulation, rather than knowledge of a single gene regulatory network. We were also concerned students may try to re-create the model seen in the background (pre) or in the lesson (post) rather than generalizing about the mechanisms of gene regulation. Conceptual models are visual representations of interconnected structures that holistically address a function or purpose. They are composed of structures in boxes that are 
connected with labeled arrows that describe the relationship (in this study, these are usually a mechanism or behavior) between the two connected concepts (Bray-Speth et al. 2014; Hmelo-Silver et al. 2007). Using the student example in Fig. 2, an operon is a structure with relationships to enzymes, promotor, DNA, and a repressor. DNA is "in" the operon which "produces" enzymes. For the purposes of this study, a word outlined in a box was deemed a structure and a relationship was represented by an arrow. Conceptual models are valuable and valid tools for measuring student understanding and have been used in the context of cellular systems (Akçay 2017; Bergan-Roller et al. 2018; Lee et al. 2015; Ummels et al. 2015; Verhoeff et al. 2008). Here, we used conceptual models to represent students' mental model of the regulation of gene expression and how their understanding was affected by the lesson. Students' pre models were constructed at the beginning of the class period, without notes or the reading, and their post models were constructed following the lesson and before students left the classroom, again without notes. Both models were created on paper.

\section{Analysis}

We analyzed conceptual models to determine changes in students' mental models induced by completing a computer-based lesson about the lac operon system of gene regulation in prokaryotes. We did not compare students' models to an "expert" model of the system. For each students' models, we examined pre to post differences ( $n=289$ models) by analyzing their entire conceptual models as well as individual structures within their conceptual models (Bergan-Roller et al. 2018). The conceptual models were analyzed for quantity of structures, quantity of relationships, average correctness, and interconnectivity. An example of a student-generated conceptual model with annotations, how it was analyzed, and related model metrics are illustrated in Fig. 2. Quantity of structures is the number of structures (boxes) in a conceptual model. Quantity of relationships is the number of relationships (arrows) in a conceptual model. As a surrogate measure for overall correctness, we quantified the average correctness of all relationships in students' models. Average correctness was determined by scoring individual relationships for correctness on a scale from 1 to 3 (Supplemental Materials S2) and calculating the average correctness for the entire model (Dauer et al. 2013). This calculation assumes that students build a fragmented mental model of a complex system as they develop their understanding the system dynamics from the interaction of many structures. Interconnectivity was determined using the web-like causality index (WCI) that measures the number of structures with multiple

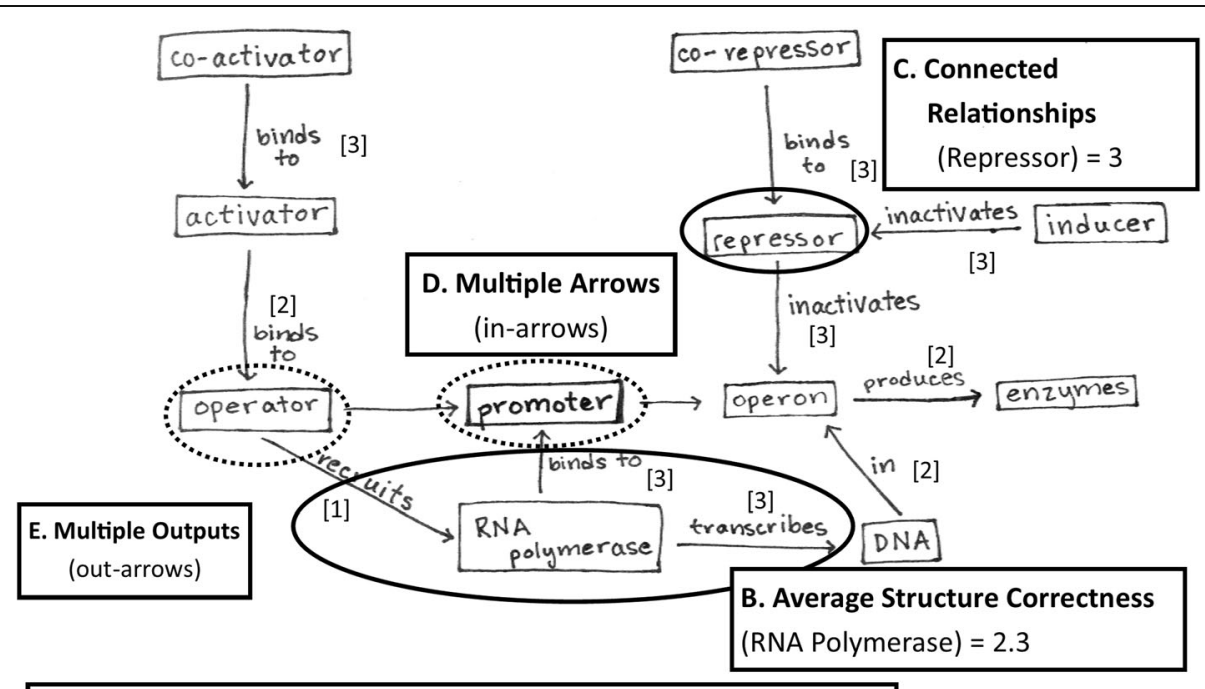

A. Whole Model Metrics

Quantity of Structures (boxes) $=11$

Quantity of Relationships (arrows) $=12$

Quantity of Described Relationships (labeled arrows) $=10$

Quantity of Undescribed Relationships (unlabeled arrows) $=2$

Average Model Correctness $=2.7$

Model Interconnectivity $(\mathrm{WCI})=1.6$

Fig. 2 Student-generated conceptual model with annotations of how models were analyzed. Correctness scores ( 1 is incorrect, 2 is correct but lacking technical accuracy, 3 is scientifically accurate) are shown in brackets next to each described relationship 
causes (Fig. 2 box D) or effects (Fig. 2 box E) (Plate 2010). WCI is the sum of two proportions: multiple causes divided by total structures and multiple effects divided by total structures, and ranges from 0 (linear models) to 2 (web-like).

A local environment analysis looked at individual structures for presence of relationships, quantity of connected relationships, and structure correctness. Quantity of connected relationships was the number of relationships (arrows) connected to a specific structure (Fig. 2, box C). Structure correctness was the average correctness of relationships connected to a specific structure (Fig. 2, box B). In Fig. 2, the average structure correctness of RNA polymerase is 2.3 because the connection "binds to promoter" is scientifically accurate (3), as is "transcribes DNA" (3), but "operator recruits RNA polymerase" is inaccurate (1). High scores for quantity and correctness of relationships indicated that the student embedded the structure in their mental model in an integrative way as opposed to just adding to the periphery of the model.

Nearly all of the 338 consenting students created a model with at least three structures during the pre-lesson (337) and the post-lesson (334) and could be analyzed for the quantity of structures. There were 292 students (pre) and 302 students (post) who created models with more than one described relationship (labeled arrow) that could be analyzed for quantity of relationships and average correctness of the described relationships, as well as interconnectivity, and local environment of context-specific structures (post only). There were 289 students who created models that could be assessed for change in relationship quality and change in local environment for provided structures.

We examined whether differences existed between fall 2015 and spring 2016 terms based on students' pre model metrics (numbers of structures and relationship, quality of relationships, interconnectedness) and included gender and ACT scores as covariates. For every metric, there was no significant difference between the terms and therefore we pooled data across terms. The data were analyzed using a linear mixed effects model with repeated measures (students) and additive and interactive models were fit for change from pre to post. The additive models provided a better data fit for each metric as determined by the AIC values and this model was used. Effect sizes were calculated using Hedges $g_{\text {av }}$ when comparing pre to post with repeated measures (Cohen 1988). Change in presence of structures was determined using a binomial logistic regression with the presence/absence on the pre model to normalize the data.

\section{Results}

Overall, conceptual models demonstrated that students started with incomplete, mostly inaccurate mental models of regulation of gene expression. Following the lesson, students created conceptual models that represented mental models containing more structures and relationships while concurrently improving the quality of the relationships. In this section, we revisit our research questions to examine how students' models changed because of the modeling lesson.

\section{Changes in scope and quality of students' conceptual models}

Pre-lesson conceptual models consisted of an average of 8.2 structures (nine were provided), and $50 \%$ of students (155) included nine or more structures in their pre models. Students had a varying number (average 7.9) of relationships connecting these structures (Table 1). Most of these relationships (range 74-80\%) were labeled, and we analyzed these labeled relationships for quality, using a rubric for this purpose with values of incorrect (1), plausible but lacking technical accuracy (2), and scientifically accurate (3). On the pre models, students used low quality, mostly incorrect, relationships $(1.7, \mathrm{SE}=0.03)$. For a median student, it was common to have relationships that scored, for example, 3, 3, 2, 2, 1, 1, 1, 1, suggesting good knowledge of some relationships but overall vague or inaccurate relationships dominating. Students' pre models also had low interconnectedness as the average $\mathrm{WCI}$ was $0.32(\mathrm{SE}=0.01$, highest possible $=$ 2 ), suggesting most of their structures had a single cause or effect arrow rather than web-like with multiple arrows associated with each structure.

Post-lesson conceptual models were larger and of higher quality (Table 1, Fig. 3). The number of structures significantly increased from pre to post $(t(289)=$ $6.27, p<.001)$ to 9.3 structures $(\mathrm{SE}=0.16)$ with a medium effect size $\left(g_{\mathrm{av}}=0.39\right)$. The majority of students (54\%) increased the number of structures used in their models. More students (207 students, 63\%) included at least nine structures on the post-lesson conceptual models. The number of total relationships increased $\left(t(289)=4.59, p<.01, g_{\mathrm{av}}=0.28\right)$ to 8.9 relationships $(\mathrm{SE}=0.17)$ with $54 \%$ of students increasing the number of relationships used in their models. There was no change in WCI $\left(t(289)=-1.934, p=.054, g_{\text {av }}=0.13\right)$ with $48 \%$ of students decreasing in interconnectedness, $11 \%$ staying the same, and $38 \%$ increasing.

There was a significant pre to post increase in average relationship correctness $(t(289)=6.436, p<.001)$ from 1.7 to 1.9 with a medium effect size $\left(g_{\mathrm{av}}=0.41\right.$, Table 1$)$. These models were, on average, below the 2 threshold. We focused on 2 because models with an average correctness below 2 contained incorrect relationships and suggested students' mental models also had incorrect relationships. The number of students who averaged a 2 or above on the pre models (94 students, 33\%) increased on the post conceptual models to 153 students (53\%). Of 
Table 1 Differences in number and quality of represented structures and relationships between pre- and post-lesson conceptual models (SE $=$ standard error of the mean)

\begin{tabular}{lll}
\hline Metric & Pre-lesson & Post-lesson \\
\hline Average number of represented structures (9 provided) & $8.2(\mathrm{SE}=0.15)$ & $9.3(\mathrm{SE}=0.16)^{* *}$ \\
Average number of relationships & $7.9(\mathrm{SE}=0.19)$ & $8.9(\mathrm{SE}=0.17)^{*}$ \\
Average correctness (3 high-1 low) & $1.7(\mathrm{SE}=0.03)$ & $1.9(\mathrm{SE}=0.03)^{* *}$ \\
Average interconnectivity $(\mathrm{WCl})$ & $0.32(\mathrm{SE}=0.01)$ & $0.30(\mathrm{SE}=0.01)$ \\
\hline
\end{tabular}

${ }^{*} p<.05,{ }^{* *} p<.001$

the 289 student pre and post models that could be assessed for change in relationship quality, 63\% increased their average correctness, $6 \%$ stayed the same, and $31 \%$ decreased. Most students increased in both number of relationships and relationship quality (Fig. 4). Nearly half of 289 student models $(44 \%, n=128)$ increased in size and increased in quality of relationships and $19 \%(n=54)$ reduced model size while concomitantly improving relationship quality. Another $22 \%$ ( $n=$ 64 ) increased the size of models by labeling more arrows at the same time these labels were of lower quality. These changes in structures, relationships, and relationship correctness demonstrated that students' mental models of the lac operon system had a small to medium positive effect on the number of structures and quality of connections, a change that can be attributed to the computational modeling lesson.

\section{Changes in context specificity and connectivity in students' models}

A local environment analysis of the structures helped determine how students' models changed to accommodate the changes in relationship number and quality. The provided structures were general biology structures common to many gene regulatory systems and were present in most student models (55-89\% of models). Provided structures generally appeared in more pre than post models (Table 2). Two general structures, mRNA and operon, appeared in $5 \%$ and $13 \%$, respectively, of pre models and increased significantly in presence $(11 \%$ and $23 \%$ ) in post models. The number of labeled relationships associated with structures was generally below two, indicating a structure that was connected by a single arrow (either cause or effect) and peripheral rather than integrated into their model. Structures such as activator, operator, promoter, and repressor often had two or more arrows (relationships greater than or equal to 2) connected to them and were more central to students' conceptual models. The number of relationships associated with a given structure changed little from pre to post for provided structures (Table 2), with an unchanged or declining trend of number of relationships. While the number of relationships remained the same or decreased, the quality of the relationships (correctness) increased significantly for most of the provided general structures (Table 2). Co-activator, DNA, and repressor had an average correctness greater than 2 indicating these structures had more correct than incorrect relationships associated with them. Other structures approached an average correctness of 2 but models still had more incorrect than correct relationships associated with these structures.

Context-specific structures, such as lac operon, allolactose, and cAMP, were present in fewer than $10 \%$ of 


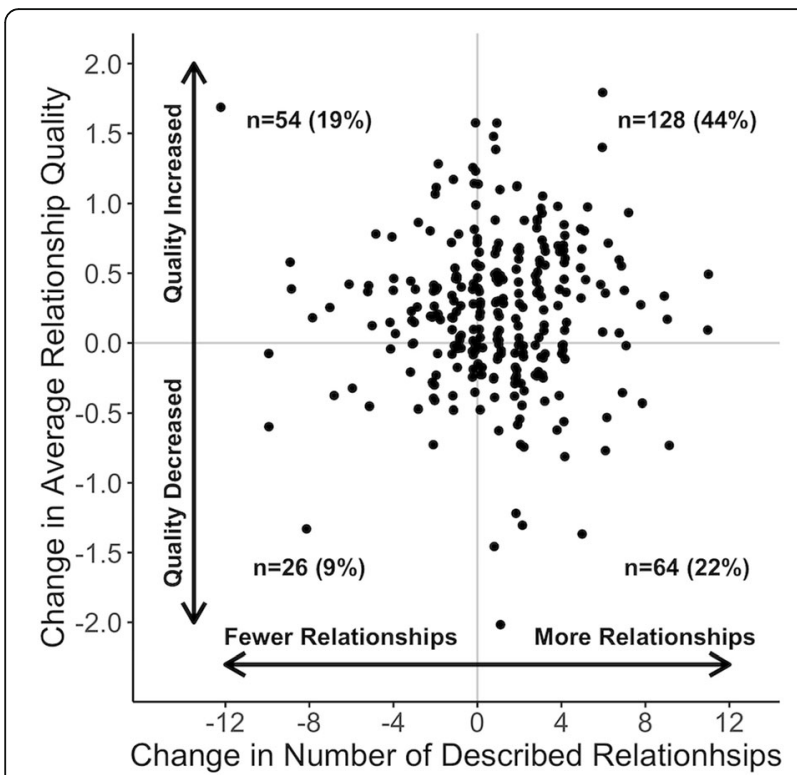

Fig. 4 Change in size and quality of student-generated conceptual models from a pre-lesson to post-lesson activity. Size was quantified as number of labeled arrows (relationships) that could be scored for the quality of the description. Quality for each relationship in a student model was assessed on an incorrect (1), vague (2), and technically correct (3) score and the change represented the change in average model score per student from pre to post

pre models, as we expected. After observing lac operonspecific terms in many models, we chose to analyze how students incorporated them as evidence of how students integrated these structures into their general gene regulation mental models. These structures appeared more frequently on post models, although they were only present in approximately $20 \%$ of the post models (Table 3 ). When students included context-specific structures, they generally integrated these structures with two or more connections on post conceptual models (Table 3). Lac repressor and glucose had an average of 3 and 2.6 relationships, respectively. In addition to integrating context-specific structures rather than adding them peripherally, students labeled these relationships with high quality annotations. The quality of the relationships connected to contextspecific structures were generally greater than two, demonstrating mainly correct relationships. Context-specific structures were not as common as the general, provided structures, but when present, students integrated them into their models with more and higher quality relationships than the general structures.

\section{Discussion}

The lac operon system is a relatively simple system with large implications for understanding cellular mechanisms of the regulation of gene expression. The system lends itself to computational modeling, in particular, because there are relatively few structures that interact in response
Table 2 Local environment analysis (presence, average number of relationships, and average correctness) of provided structures in students' conceptual models ( $n=289$ students). Relationships are number of labeled arrows connected to the structure and correctness is the quality of those relationships. Models were only included in the analysis if the student created a conceptual model that contained at least 1 labeled relationship on the preand post-lesson activity

\begin{tabular}{|c|c|c|c|c|}
\hline Structure & Assessment & Presence (\%) & Relationships & Correctness \\
\hline \multirow[t]{2}{*}{ Activator } & Pre & 81.8 & 2.2 & 1.7 \\
\hline & Post & $72.0^{*}$ & 2.1 & $1.9^{* *}$ \\
\hline \multirow[t]{2}{*}{ Coactivator } & Pre & 67.2 & 1.3 & 1.8 \\
\hline & Post & $55.0^{* *}$ & 1.3 & $2.0^{*}$ \\
\hline \multirow[t]{2}{*}{ Corepressor } & Pre & 67.2 & 1.3 & 1.9 \\
\hline & Post & $57.1^{*}$ & 1.3 & 2.0 \\
\hline \multirow[t]{2}{*}{ DNA } & Pre & 89.1 & 1.9 & 1.9 \\
\hline & Post & $79.6^{* *}$ & 1.8 & $2.1^{*}$ \\
\hline \multirow[t]{2}{*}{ Inducer } & Pre & 64.7 & 2.0 & 2.1 \\
\hline & Post & 55.9 & 1.4 & $1.9^{* *}$ \\
\hline \multirow[t]{2}{*}{ Operator } & Pre & 68.7 & 2.3 & 1.7 \\
\hline & Post & 73.3 & 2.4 & $1.9^{*}$ \\
\hline \multirow[t]{2}{*}{ Promoter } & Pre & 64.7 & 2.1 & 1.7 \\
\hline & Post & 63.8 & 2.0 & $1.9^{*}$ \\
\hline \multirow[t]{2}{*}{ Repressor } & Pre & 86.0 & 2.1 & 1.8 \\
\hline & Post & 77.8 & 2.2 & $2.1^{* *}$ \\
\hline \multirow[t]{2}{*}{ RNA polymerase } & Pre & 84.5 & 2.1 & 1.7 \\
\hline & Post & 86.6 & 1.9 & $1.9^{*}$ \\
\hline
\end{tabular}

to environmental cues and relatively simple logical rules that result in biologically realistic, observable patterns. This study focused on how students' mental models of gene regulation changed as they observed the outcomes emerging from dynamic, interactive components, as

Table 3 Local environment analysis (presence, average number of relationships, and average correctness) of context-specific structures that were not provided in instructions ( $n=329$ models). Relationships are the number of labeled arrows connected to the structure and correctness is the quality of those relationships. Only post-lesson models were analyzed because presence on pre-lesson models was below 10\%

\begin{tabular}{lllll}
\hline Structure & Assessment & Presence (\%) & Relationships & Correctness \\
\hline Allolactose & Post & 22.2 & 2.0 & 2.2 \\
CAMP & Post & 24.6 & 1.9 & 2.1 \\
CAP & Post & 25.8 & 2.0 & 2.3 \\
Glucose & Post & 19.2 & 2.6 & 2.0 \\
Lac operon & Post & 21.0 & 1.5 & 1.7 \\
Lac repressor & Post & 14.6 & 3.0 & 2.0 \\
Lactose & Post & 24.3 & 1.5 & 1.9 \\
\hline
\end{tabular}


represented through students' conceptual models. We hypothesized that completing computational modeling activities in a specific context would improve students' knowledge of the structures and relationships of gene regulation by reinforcing, replacing, removing, and improving quality for the relationships within the system. Students demonstrated a better understanding of gene regulation by representing their larger (structures and relationships) and higher quality mental model. Following the modeling lesson, more than half of students constructed larger conceptual models with significantly more structures and relationships (medium effect size, $g_{\text {av }}=$ 0.28 and 0.39 , respectively). Larger conceptual models are reflective of a greater number of structures in students' mental model of the system (Ifenthaler et al. 2011), as would be expected from spending time engaging with a biological system. In other studies, increased model size was a common outcome as students encountered new content (Bray-Speth et al. 2014; Dauer et al. 2013; Mintzes and Quinn 2007). Bigger is not necessarily better if new knowledge is weakly connected to existing knowledge or stored in isolation. Accreting new knowledge needs to be accompanied by re-constructing their mental model to account for the new knowledge that relate those new structures in a biologically consistent model (Mintzes and Quinn 2007).

In our study, students' mental models increased in size and improved in relationship quality: $63 \%$ of students significantly increased their average model correctness (medium effect size, $g_{\text {av }}=0.41$, Fig. 4). Approximately half of the students still retained incorrect and vague relationships within their mental models. For the other half of students, the lac operon computational lesson reinforced some relationships and challenged students to replace or remove other relationships and forced them to restructure their model (Pearsall et al. 1997; Reinagel and Bray Speth 2016). Consequently, a computational model reinforced some mental model relationships by showing the result of those interactions. For example, activation of the catabolite activator protein (CAP) by cAMP can result in transcription of the operon. In a general model, this would mean that a co-activator binds to an activator and can result in transcription of the operon to mRNA. This can emphasize the relationship between these two structures and their outcome and may cause students to reconsider their mental model of how an operon can be induced by molecular interactions.

At the same time, student models increased in size and quality, their models were also changing in composition as they learned this specific system. Analysis of the local environment provided insight into the specific areas of learning that occurred during the computerbased modeling lesson. Generally, students' inclusion of general structures (e.g., activator, inducer) decreased or remained the same, while the inclusion of contextspecific structures (e.g., allolactose, cAMP) increased (Tables 2 and 3). More than half of students (58\%) included at least one context-specific structure on their post models without prompting. Most of these students still included more general structures (the structures provided) although $23 \%$ ( $n=76$ students) included an equal or greater number of context-specific structures. Overall, this suggests a replacement of generic terms for context-specific terms rather than addition of new context-specific terms as modifiers to a generic model. This highlights the variation in knowledge building as new and existing knowledge are actively integrated (Nenciovici et al. 2019). The post conceptual models captured the process whereby students reinforced some relationships and structures and replaced some structures with lac-specific structures; at the same time, they have removed incorrect connections and improved the quality of other relationships.

Students included context-specific structures with greater centrality than would be expected if these were simply adding to a general model. For most of the context-specific structures, the number of relationships was at or above 2, describing a structure embedded within the model rather than peripheral (Table 3). A peripheral structure would be connected with a single arrow and represent a beginning or end of the idea, rather than internal to the model. Low centrality structures (peripheral) like coactivator and corepressor (Table 2) suggest most students connected them as instructed but added them peripherally rather than central to showing the model purpose. Some structures, like lactose and glucose, were expected to have low centrality since they were environmental conditions and represented a "start" point to the model. Lactose was often included in this way (Table 3) while glucose was often connected with multiple relationships suggesting greater clarity for integration of lactose than glucose.

One can imagine that a student would show a decrease in relationship quality if they struggled to incorporate the new structures into their mental model. However, we noted that overall model quality (average correctness) increased and the general structures that were retained in students' mental models increased in quality. For example, activator and repressor structures were included in $82 \%$ and $86 \%$ pre models. These two structures were present in $72 \%$ and $78 \%$ of post-lesson models with the same number of relationships, but significantly higher correctness, 1.9 and 2.1 (Table 2). While these terms were retained in students' post models, their quality of relationships suggests the lesson supported their learning of how activators and repressors impacted gene expression. Interestingly, only the quality of relationships connected to inducer decreased significantly, possibly because inducer was a minimally integrated in the 
computational lac operon lesson. Because contextspecific structures were infrequently included on pre models, we were unable to determine the change in quality of relationships. We imagine that if students were asked to include context-specific terms in their pre models and if the purpose of the model was constrained to explaining the lac operon system, relationship quality would have been low because most students likely had little prior knowledge of these structures. What is surprising is that on students' post-lesson models, they used high quality relationships suggesting students' mental models changed rapidly to incorporate the contextspecific structures and replace the generic structures.

\section{Conclusions}

The overall changes in students' conceptual models, from small and general to larger, more context-specific, and higher quality, suggest multiple changes in their understanding of the functionality of the system (Reinagel and Bray Speth 2016; Verhoeff et al. 2008). As Reinagel and Bray-Speth (2016) showed with conceptual models of gene-to-phenotype models, students improved in their ability to apply a generalized model to a specific context. We assume that students enhanced their understanding of the system functionality by first creating a conceptual model, then using a computational model to simulate the dynamics, because students would have engaged their mental model of gene regulation before conducting thought experiments to predict and explain the dynamics. This study did not examine the application of lac operon knowledge to a novel gene regulatory system and it would be interesting to determine how students use their knowledge of system dynamics to generalize about other regulatory networks. That is, does a students' mental model of a system such as the lac operon system provide the foundation for student reasoning about other prokaryotic and eukaryotic gene regulatory systems? Determining students' abilities to generalize their systems thinking offers a cautionary tale. It is possible for students to develop an accurate mental model of system structures without understanding the mechanisms that give rise to the observed phenomena (Louca and Zacharia 2012). Pedagogical considerations, either embedded in the lesson or in follow-up by instructors, become paramount to ameliorate this concern. While the study is lacking consideration of systems thinking extrapolation, students have established a mental model of gene regulatory networks in prokaryotes that could be further harnessed by instructors.

The postsecondary biology community continues to seek instructional methods that can improve students' core competencies in modeling and simulation related to biological systems (AAAS 2011). Instructors should consider how students are learning in these environments and the opportunities for student to change their conceptual understanding of system structures, relationships, and dynamics that underlie the phenomena. By coupling conceptual models and computational modeling, instructors ensure students' mental models are informed by dynamic interactions and students can be challenged more than by conceptual models alone (Seel 2017).

While time-consuming, modeling (including constructing and revising conceptual and computational models) affords benefits for students' conceptual change. Supporting students' modeling abilities likely requires a concerted effort over multiple class periods, courses, and years. We are unaware of research on longitudinal changes in students' modeling ability at the postsecondary level, possibly because broad integration of modeling into biology curricula is rare (see Thompson et al. 2013 for quantitative integration). Longitudinal studies into integrative curricula can provide critical feedback to instructors about student modeling abilities over time and inform how to introduce critical skills like mathematically relating relationships, how and when to revise models, and using models to fuel science discovery.

Modeling is an interdisciplinary skill (Brewe 2008; J. K. Gilbert 2004; Hallström and Schönborn 2019) that can be scaffolded within a course by the instructor who emphasizes the iterative and repetitive nature of modeling. The repetition of generating, evaluating, and modifying models will enculturate this method of thinking about science through the lens of models (Windschitl et al. 2008), much the way biologists approach their experimental design (Nersessian 2009). Undoubtedly, it requires a commitment by the instructor to purposefully integrate modeling, not just models, into their pedagogy.

The benefit of an integrated course for the student is a more sophisticated mental model that can be generalized to other phenomena. Conceptual and computational models feedback to students' mental model. When deciding to use conceptual models to elicit students' mental models, we want to share a few considerations supported by this research. Larger models may not be indicative of better mental models, especially if the relationships are missing or incorrect. Importantly, conceptual models at one time point will help identify the structures students have integrated within their model as these are likely more central to students' mental model than peripheral structures. Repeated conceptual modeling activities will inform the instructor about what structures and relationships have been reinforced and how students are attempting to connect new knowledge into their existing model by replacing and eliminating relationships.

As students accrete new knowledge and re-construct their existing mental models of the system, their conceptual models will increase in size, connectivity, and 
(hopefully) quality. Knowing the structures can help in discovery of the relationships between those structures as students inquire about the system dynamics (Lazonder et al. 2009) and apply their model to solve problems (Seel 1995). Computational modeling activities that are properly structured as inquiry activities will reinforce students' conceptual understanding of presence and quality of relationships. Consequently, these activities will re-emphasize the quantitative nature of the relationships among structures and reinforce those same relationships in the students' mental models. Embedding computational models into curricula can help students visualize and experience the dynamic nature of systems in a way that productively enhances their mental model of the phenomena.

The strength of relationships within students' mental models will become useful as they encounter the lac operon in subsequent courses, like genetics, biochemistry, and evolution (Cooper 2015). The students that developed a robust, interconnected model would likely have an enhanced ability to retrieve their conceptual model of regulation of gene expression (Dauer and Long 2015) and would be prepared to expand, improve, and apply this model to new systems. Introductory students are pursuing diverse academic pathways, and instructors should consider their role in developing students' abilities to apply their understanding of gene regulation to other scenarios and the importance of modeling in discovering these generalizations. Feedback mechanisms, emergent outcomes, and environmentally sensitive interactions are applicable in the lac operon, gene regulation, and biological system writ large. This lesson, and other computational modeling lessons, allows students to "break" the system as a way of exploring complex interactions and outcomes as they construct knowledge of how systems operate dynamically.

\section{Abbreviations}

CAMP: Cyclic adenosine monophosphate; CAP: Catabolite activator protein; DNA: Deoxyribonucleic acid; mRNA: Messenger ribonucleic acid;

RNA: Ribonucleic acid; WCl: Web-like causality index

\section{Acknowledgements}

We thank Dr. Steven Harris (UNL), James Buescher, and the teaching assistants for their help in implementing the computational lessons as well as the mapping activity. We thank Suhair BarBar Askar, Katerina Lozano, and Taylor Uhlir for their logistical and technical support. We thank Dr. Erica Stuber and Dr. Christopher Chizinski for their advice on statistics, Collin Jaeger for his help in analyzing data, and Dr. Kate Wright for providing input on the correctness rubric. And we thank the reviewers who provided exceptional feedback that improved the quality of this manuscript.

\section{Authors' contributions}

All authors were involved in study design. NG, HBR, TH, and JD developed the materials for the study. JD, HBR, and NG managed the data collection and data entry efforts, and MK cleaned the dataset and provided interpretation. JD, HBR, and GK conducted the data analysis and wrote the introduction, results, and the discussion of the manuscript. TH contributed to the editing of the manuscript and aided in the results interpretation and scope of the discussion. All authors read and approved the final manuscript.

\section{Funding}

This study was funded by the National Science Foundation under Grant No. DUE 1432001 to TH and JD. The funders did not play a role in the design and collection, analysis, interpretation of the data, or manuscript writing.

\section{Availability of data and materials}

The datasets used and/or analyzed during the current study are available from the corresponding author on reasonable request.

The Cell Collective Learn lac operon computational modeling lesson can be found at https://learn.cellcollective.org, in Crowther et al. 2019, or through request from the corresponding author. The conceptual modeling activities (pre/post) and the correctness rubric used to analyze student models are available in the supplementary information files.

\section{Competing interests}

TH is the majority stakeholder in a company, Discovery Collective, Inc., that has proprietary rights to the software used in this project which is currently under development.

\section{Author details}

${ }^{1}$ School of Natural Resources, University of Nebraska-Lincoln, 3310 Holdrege St, 524 Hardin Hall, Lincoln, NE 68583, USA. ²Department of Biological Sciences, Northern Illinois University, DeKalb, IL 60115, USA. ${ }^{3}$ Department of Science, Valley City State University, Valley City, ND 58072, USA. ${ }^{4}$ Department of Biochemistry, University of Nebraska-Lincoln, Lincoln, NE 68583, USA.

Received: 9 January 2019 Accepted: 11 October 2019

Published online: 19 November 2019

\section{References}

AAAS. (2011). Vision and change in undergraduate biology education: A call to action

Abou-Jaoudé, W., Traynard, P., Monteiro, P. T., Saez-Rodriguez, J., Helikar, T., Thieffry, D., \& Chaouiya, C. (2016). Logical modeling and dynamical analysis of cellular networks. Frontiers in genetics, 7, 94.

Akçay, S. (2017). Prospective elementary science teachers' understanding of photosynthesis and cellular respiration in the context of multiple biological levels as nested systems. Journal of Biological Education, 51(1), 52-65 https:// doi.org/10.1080/00219266.2016.1170067.

Bergan-Roller, H., Galt, N. J., Helikar, T., \& Dauer, J. (2018). Using concept maps to characterise cellular respiration knowledge in undergraduate students. Journal of Biological Education. https://www.tandfonline.com/doi/abs/10. 080/00219266.2018.1541001

Bodemer, D., Ploetzner, R., Bruchmuller, K., \& Hacker, S. (2005). Supporting learning with interactive multimedia through active integration of representations. Instructional Science, 33(1), 73-95.

Bray-Speth, E., Shaw, N., Momsen, J., Reinagel, A., Le, P., Taqieddin, R., \& Long, T. (2014). Introductory biology students' conceptual models and explanations of the origin of variation. CBE-Life Sciences Education, 13(3), 529-539.

Brewe, E. (2008). Modeling theory applied: Modeling Instruction in introductory physics. American Journal of Physics, 76(12), 1155-1160 https://doi.org/10. $1119 / 1.2983148$.

Brownell, S. E., Freeman, S., Wenderoth, M. P., \& Crowe, A. J. (2014). BioCore Guide: A tool for interpreting the core concepts of Vision and Change for biology majors. CBE-Life Sciences Education, 13(2), 200-211 https://doi.org/10. 1187/cbe.13-12-0233.

Cohen, J. (1988). Statistical power analysis for the behavioral sciences (2nd ed.). Hillsdale: Erlbaum.

Cooper, R. A. (2015). Teaching the big ideas of biology with operon models. The American Biology Teacher, 77(1), 30-39.

Crowther, A., Bergan-Roller, H. E., Galt, N. J., Appleby, L., Dauer, J. T., \& Helikar, T. (2019). Discovering prokaryotic gene regulation by building and investigating a computational model of the lac operon. CourseSource, 6 https://doi.org/10. 24918/cs.2019.4.

Dauer, J., \& Dauer, J. (2016). A framework for understanding the characteristics of complexity in biology. International Journal of STEM Education, 3(1), 13.

Dauer, J., \& Long, T. M. (2015). Long-term conceptual retrieval by college biology majors following model-based instruction. Journal of Research in Science Teaching, 52(8), 1188-1206 https://doi.org/10.1002/tea.21258. 
Dauer, J., Momsen, J. L., Speth, E. B., Makohon-Moore, S. C., \& Long, T. M. (2013). Analyzing change in students' gene-to-evolution models in college-level introductory biology. Journal of Research in Science Teaching, 50(6), 639-659.

de Jong, T., \& van Joolingen, W. R. (1998). Scientific discovery learning with computer simulations of conceptual domains. Review of Educational Research, 68(2), 179-201 https://doi.org/10.3102/00346543068002179.

Eaton, C. D., Callender, H. L., Dahlquist, K. D., LaMar, M. D., Ledder, G., \& Schugart, R. C. (2019). A "Rule of Five" framework for models and modeling to unify mathematicians and biologists and improve student learning. Problems, Resources, and Issues in Undergraduate Mathematical Sciences (PRIMUS), 29(8), 799-829 https://doi.org/10.1080/10511970.2018.1489318.

Esmaeili, A., Davison, T., Wu, A., Alcantara, J., \& Jacob, C. (2015). PROKARYO: An illustrative and interactive computational model of the lactose operon in the bacterium Escherichia coli. BMC Bioinformatics, 16(1), 311 https://doi.org/10. 1186/s12859-015-0720-z.

Fretz, E. B., Wu, H.-K., Zhang, B., Davis, E. A., Krajcik, J. S., \& Soloway, E. (2002). An investigation of software scaffolds supporting modeling practices. Research in Science Education, 32(4), 567-589.

Fuhrmann, T., Schneider, B., \& Blikstein, P. (2018). Should students design or interact with models? Using the Bifocal Modelling Framework to investigate model construction in high school science. International Journal of Science Education, 0(0), 1-27. https://doi.org/10.1080/09500693.2018.1453175

Garfunkel, S., \& Montgomery, M. (Eds.). (2016). GAIMME Report: Guidelines for assessment \& instruction in mathematical modeling education. Bedford: Consortium for Mathematics and Its Applications http://www.siam.org/ reports/gaimme.php.

Gilbert, J. K. (2004). Models and modelling: Routes to more authentic science education. International Journal of Science and Mathematics Education, 2(2), 115-130.

Gilbert, S. W. (1991). Model building and a definition of science. Journal of Research in Science Teaching, 28(1), 73-79.

Hallström, J., \& Schönborn, K. J. (2019). Models and modelling for authentic STEM education: reinforcing the argument. International Journal of STEM Education, 6(1), 22 https://doi.org/10.1186/s40594-019-0178-z.

Helikar, T., Cutucache, C. E., Dahlquist, L. M., Herek, T. A., Larson, J. J., \& Rogers, J. A. (2015). Integrating interactive computational modeling in biology curricula. PLoS Computational Biology, 11(3), e1004131 https://doi.org/10. 1371/journal.pcbi.1004131

Helikar, T., Kowal, B., McClenathan, S., Bruckner, M., Rowley, T., Madrahimov, A., et al. (2012). The Cell Collective: Toward an open and collaborative approach to systems biology. BMC Systems Biology, 6(1), 96 https://doi.org/10.1186/ 1752-0509-6-96.

Hmelo-Silver, C. E., Marathe, S., \& Liu, L. (2007). Fish swim, rocks sit, and lungs breathe: Expert-novice understanding of complex systems. Journal of Learning Science, 16(3), 307-331.

Ifenthaler, D., Masduki, I., \& Seel, N. M. (2011). The mystery of cognitive structure and how we can detect it: tracking the development of cognitive structures over time. Instructional Science, 39(1), 41-61.

Jordan, R., Gray, S., Demeter, M., Liu, L., \& Hmelo-Silver, C. (2008). Adding behavior to thinking about structures \& function. American Biology Teacher, 70(6), 329-330.

Jungck, J. R. (2011). Mathematical biology education: modeling makes meaning. Mathematical Modelling of Natural Phenomena, 6(6), 1-21.

Lazonder, A. W., Wilhelm, P., \& van Lieburg, E. (2009). Unraveling the influence of domain knowledge during simulation-based inquiry learning. Instructional Science, 37(5), 437-451 https://doi.org/10.1007/s11251-008-9055-8.

Lee, S., Kang, E., \& Kim, H.B. (2015). Exploring the impact of students' learning approach on collaborative group modeling of blood circulation. Journal of Science Education and Technology, 24(2-3), 234-255 https:/doi.org/10.1007/s10956-014-9509-5.

Louca, L. T., \& Zacharia, Z. C. (2012). Modeling-based learning in science education: cognitive, metacognitive, social, material and epistemological contributions. Educational Review, 64(4), 471-492.

Mintzes, J., \& Quinn, H. J. (2007). Knowledge restructuring in biology: Testing a punctuated model of conceptual change. International Journal of Science and Mathematics Education, 5, 281-306.

Mulder, Y. G., Bollen, L., de Jong, T., \& Lazonder, A. W. (2016). Scaffolding learning by modelling: The effects of partially worked-out models. Journal of Research in Science Teaching, 53(3), 502-523 https://doi.org/10.1002/tea.21260.

Nenciovici, L., Allaire-Duquette, G., \& Masson, S. (2019). Brain activations associated with scientific reasoning: a literature review. Cognitive Processing, 20, 139-161 https://doi.org/10.1007/s10339-018-0896-z.

Nersessian, N. J. (1999). Model-based reasoning in conceptual change. In L. Magnani, N. J. Nersessian, \& P. Thagard (Eds.), Model-Based Reasoning in
Scientific Discovery (pp. 5-22). Boston: Springer US https://doi.org/10.1007/ 978-1-4615-4813-3_1.

Nersessian, N. J. (2009). How do engineering scientists think? Model-based simulation in biomedical engineering research laboratories. Topics in Cognitive Science, 1(4), 730-757 https://doi.org/10.1111/j.1756-8765.2009.01032.x.

Odenbaugh, J. (2005). Idealized, inaccurate but successful: A pragmatic approach to evaluating models in theoretical ecology. Biology and Philosophy, 20(2-3), 231-255.

Pearsall, N. R., Skipper, J. E. J., \& Mintzes, J. J. (1997). Knowledge restructuring in the life sciences: A longitudinal study of conceptual change in biology. Science Education, 81(2), 193-215.

Plate, R. (2010). Assessing individuals' understanding of nonlinear causal structures in complex systems. System Dynamics Review, 26(1), 19-33 https:// doi.org/10.1002/sdr.432

Reinagel, A., \& Bray Speth, E. (2016). Beyond the central dogma: model-based learning of how genes determine phenotypes. CBE - Life Sciences Education, 15(1), ar4.

Rumelhart, D. E., \& Norman, D. (1978). Accretion, tuning and restructuring. In J. Cotton \& R. Klatzky (Eds.), Semantic factors in cognition (pp. 37-54). Hillsdale: Erlbaum Lawerence Associates.

Rutten, N., van Joolingen, W. R., \& van der Veen, J. T. (2012). The learning effects of computer simulations in science education. Computers \& Education, 58(1), 136-153.

Schwarz, C. V., Reiser, B. J., Davis, E. A., Kenyon, L., Achér, A., Fortus, D., et al. (2009). Developing a learning progression for scientific modeling: Making scientific modeling accessible and meaningful for learners. Journal of Research in Science Teaching, 46(6), 632-654.

Seel, N. M. (1995). Mental models, knowledge transfer, and teaching strategies. Journal of Structural Learning, 12(3), 197-213.

Seel, N. M. (2017). Model-based learning: a synthesis of theory and research. Educational Technology Research and Development, 65(4), 931-966 https://doi. org/10.1007/s11423-016-9507-9.

Shavelson, R. J., Ruiz-Primo, M. A., \& Wiley, E. W. (2005). Windows into the mind. Higher Education, 49(4), 413-430.

Sins, P. H. M., Savelsbergh, E. R., \& van Joolingen, W. R. (2005). The difficult process of scientific modelling: An analysis of novices' reasoning during computer-based modelling. International Journal of Science Education, 27(14), 1695-1721 https://doi.org/10.1080/09500690500206408.

Smetana, L. K. \& Bell, R. L. (2012). Computer simulations to support science instruction and learning: A critical review of the literature. International Journal of Science Education, 34(9), 1337-1370 https:/doi.org/10.1080/09500693.2011.605182.

Soderberg, P., \& Price, F. (2003). An examination of problem-based teaching and learning in population genetics and evolution using EVOLVE, a computer simulation. International Journal of Science Education, 25(1), 35-55.

Stefanski, K. M., Gardner, G. E., \& Seipelt-Thiemann, R. L. (2016). Development of a Lac Operon Concept Inventory (LOCI). CBE-Life Sciences Education, 15(2), ar24. https://doi.org/10.1187/cbe.15-07-0162

Svoboda, J., \& Passmore, C. (2013). The strategies of modeling in biology education. Science \& Education, 22(1), 119-142.

Thompson, K. V., Cooke, T. J., Fagan, W. F., Gulick, D., Levy, D., Nelson, K. C., et al. (2013). Infusing quantitative approaches throughout the biological sciences curriculum. International Journal of Mathematical Education in Science and Technology, 44(6), 817-833.

Ummels, M. H. J., Kamp, M. J. A., de Kroon, H., \& Boersma, K. T. (2015). Designing and evaluating a context-based lesson sequence promoting conceptual coherence in biology. Journal of Biological Education, 49(1), 38-52 https://doi. org/10.1080/00219266.2014.882380.

Vattam, S. S., Goel, A. K., Rugaber, S., Hmelo-Silver, C. E., Jordan, R., Gray, S., \& Sinha, S. (2011). Understanding complex natural systems by articulating structure-behavior-function models. Journal of Educational Technology and Society, 14(1), 66-81.

Verhoeff, R. P., Waarlo, A. J., \& Boersma, K. T. (2008). Systems modelling and the development of coherent understanding of cell biology. International Journal of Science Education, 30(4), 543-568 https://doi.org/10.1080/09500690701237780.

Williams, G., \& Clement, J. (2015). Identifying multiple levels of discussion-based teaching strategies for constructing scientific models. International Journal of Science Education, 37(1), 82-107 https://doi.org/10.1080/09500693.2014.966257.

Windschitl, M., Thompson, J., \& Braaten, M. (2008). Beyond the scientific method: Model-based inquiry as a new paradigm of preference for school science investigations. Science Education, 92(5), 941-967 https://doi.org/10.1002/sce.20259.

\section{Publisher's Note}

Springer Nature remains neutral with regard to jurisdictional claims in published maps and institutional affiliations. 